\title{
On Sacs containing Fœtuses and lying free in the Peritoneal Cavity of a Rabbit.*
}

By M. S. Pembrex, M.A., M.D., Lecturer on Physiology; and G. Bellingham Smith, M.B., B.S., Assistant Obstetric Physician, Guy's Hospital.

IN connection with the subject of extra-uterine pregnancy considerable interest must be attached to the fæatal sacs which have been found by various observers in the peritoneal cavity of domestic animals. Many of these cases have been recorded as extra-uterine gestation, either primary or abdominal; others have been attributed to extrusion of the foetal sacs after rupture of the uterus. Bland Sutton has maintained that the latter view explains nearly all the cases of extra-uterine gestation in animals, and in this he is supported by the recent work of Kamann.

In the case, which is now recorded, the animal had completely recovered from the peritonitis, which had apparently followed the rupture of the uterus and the escape of the foetal sacs into the peritoneal cavity.

Description of Case. A pregnant rabbit was bought for breeding in October, 1897, and between that time and June, 1898, produced four normal litters. It was noticed that the abdomen appeared to be somewhat distended after the casting of a litter. On that account and because she neglected or devoured her young she was killed within a week of the last littering. Before the abdomen was opened palpation revealed two or three discoidal bodies, which were freely moveable in the peritoneal cavity. When the abdomen was explored, five white discoidal bodies, 7 or $8 \mathrm{~cm}$. in length, 4 or $5 \mathrm{~cm}$. in width, and $2 \mathrm{~cm}$. in thickness, were found together with a few small pieces of a compact white substance. None of these bodies showed any attachment to the abdominal organs or to the peritoneum; in all but the smallest sac the head, body, and limbs of a fotus could be felt.

In order that a thorough examination of the viscera might be made, another doe rabbit of similar size, $53 \mathrm{~cm}$. long, was killed and dissected side by side as a control.

Examination of Thorax and Abdomen. There was no sign of

* Read at a meeting of the Obstetrical Society of London, July 6th, 1904. The specimens referred to were exhibited at a meeting of the Society on July 6th, 1898. Vide Trans. Obstet. Soc. London. Vol xl. 1898. p, 253. 
pleurisy; the only abnormality in the chest appeared to be some small patches of lymph "* over the left and right ventricles of the heart. The parietal and visceral peritoneum were carefully examined. The under surface of the diaphragm showed no signs of adhesions nor were any observed between the intestines and the abdominal wall. There were, however, well-marked adhesions between the coils of the cæcum, and here in addition to flakes of lymph was found a small cyst, which was $0.5 \mathrm{~cm}$. in diameter and contained a brownish fluid. The parietal peritoneum of the left and especially of the right flank showed numerous small projections of "lymph"; in the hypogastric region these were most marked and attained a length of half a centimetre. These flakes are deposits of fibrinous exudation and not the remains of ingrowths into, or of outgrowths from, the abdominal wall; stripping up the peritoneum shows that the flakes are only attached to the free surface and microscopic examination revealed no sign of placental tissue. In the case of the stomach and spleen nothing abnormal was noted, except that the latter organ was double the size of the spleen in the control rabbit. The free margins of the liver were rough and thickened and in two places were attached by adhesions to the omentum.

Generative Organs. The ovaries and Fallopian tubes were normal in appearance; there were no adhesions and the fimbriated extremities were patent and showed no signs of inflammation. The broad ligaments were thickened and in places showed patches of lymph; these flakes were numerous upon the two horns of the uterus and upon the posterior surface of the right horn about $6 \mathrm{~cm}$. from its opening into the vagina was a projection of lymph $1 \times 0.5 \mathrm{~cm}$. The two horns were slit open and examined throughout their length; no scar or sign of rupture could be seen. The projection of lymph was at first considered to be the probable site of a rupture; that portion, therefore, of the right horn of the uterus, to which the lymph was attached, was excised and examined by means of microscopic sections. No signs of scar-tissue could be found.

A further examination of the uterus, however, was more successful. On the front of the uterus just below the external junction of the two cornua was found a ridge of tissue lying nearly horizontally and resembling in appearance a scar. It started as a thickened elevation on the left horn and became thinner as it stretched across the right horn. It is $25 \mathrm{~cm}$. long, lies about $1.5 \mathrm{~cm}$. above the openings of the two horns into the vagina and is confined

*The term "lymph" is used to indicate fibrinous exudation. 


\section{Pembrey: Sacs in Peritoneal Cavity}

chiefly to the right horn. Microscopic examination of the bulbous portion of the ridge showed well-marked fibrous tissue. No such ridge could be seen in the normal uteri of the other rabbits which were examined.

General Description of the Fatal Sacs. The five sacs are flattened ovoid bodies with a smooth white surface; the remains of the placenta can, in four of the specimens, be easily felt under the surface; the placental tissue is covered by a continuation of the smooth opaque membrane which encloses the fœetus. In each case the sac is apparently composed of the fœtal membranes and a dense layer of adventitious fibrinous deposit; the larger portion of the placenta has been detached or worn away, and evidence of the former fate is forthcoming in the small pieces of compact white substance which were found in the peritoneal cavity. Microscopic examination of this substance showed clearly the remains of placental tissue embedded in fibrinous material; these sections for the sake of comparison were examined side by side with specimens of normal placenta from a rabbit.

The external surface of the sacs appeared to the naked eye to be quite devoid of blood-vessels. None of the sacs contain any free fluid, the body of the fætus being in close contact with the wall.

The Individual Sacs and their Contents. The largest sac, i., is of special interest, for it contained four fotuses, and it is probable that the impaction of these foetuses caused a rupture and the extrusion of the fœtal sacs. The outside of the common sac is roughened in places by flakes of lymph; inside there are several portions of placental tissue, some of the pieces being attached, others free. Two of the foetuses are attached by umbilical cords to the remains of the placental tissue in the wall of the sac; they are in a better state of preservation than the other two foetuses, and their bodies show two complete twists. Their cords have been twisted round and round as many as five or six times, and so tightly around the hind legs that these limbs are much twisted and almost amputated. The twists of the body and of the umbilical cord are in each case continuous and in the same spiral direction. The other two fœtuses show slight signs of previous torsion, and are not connected by umbilical cords to the sac; there, however, the remains of the cord in each case. There are no signs of putrefaction; the fotuses appear, from their size, from the development of fur upon the head and from the condition of the incisor teeth to be at full term. In each case there are patches of lymph scattered over various 
parts of the body. There is no normal colouring matter in the fotal bodies; water has evidently been absorbed from them, and some of the tissues have undergone a fatty degeneration or infiltration.

Sac ii. is $16.5 \mathrm{~cm}$. in circumference, $7 \mathrm{~cm}$. long and $5 \mathrm{~cm}$. wide. The surface is smooth with the exception of a few fibrinous projections near the placental site which can be readily distinguished by touch. The wall of the sac is translucent, and is not adherent to the fotus; the head and body can be easily distinguished by touch, but they are considerably compressed, probably by the absorption of water and the contraction of the sac.

Sac iij. is $16.5 \mathrm{~cm}$. in circumference, $6.5 \mathrm{~cm}$. long and $5 \mathrm{~cm}$. wide. The surface is smooth, but the wall of the sac is much thicker than in No. ii., and is opaque. The placental site and the various parts of the body of the fætus can be easily distinguished by touch. As in the case of sac ii., considerable compression has occurred.

Sac iv. is $15.5 \mathrm{~cm}$. in circumference, $4 . \mathrm{cm}$. wide and $6 \mathrm{~cm}$. long. The surface is smooth, and in thickness and opacity resembles No. iii. It is not possible with certainty to distinguish by touch the placental site or the various parts of the fotus. The wall of the sac is in places slightly adherent to the foetus, but can be easily detached. The sac was cut open and the fotus was found to be tightly compressed and twisted in the posterior portion of the body. The placenta could be easily distinguished, and microscopic sections showed the characteristic structure. The body of the fotus shows signs of fatty degeneration or infiltration.

Sac $v$. is $13 \mathrm{~cm}$. in circumference, $5 \mathrm{~cm}$. long and $35 \mathrm{~cm}$. wide. The walls of the sac are thin, and on section are found to be firmly adherent to the fotus, the form of which cannot be distinguished owing to the compression and fatty degeneration or infiltration. The placental site could be easily recognised before the sac was opened.

The Evidence in favour of Rupture of the Uterus and Extrusion of the Fotal Sacs. It has already been stated that direct evidence of rupture of the uterus was found. It is necessary, however, to consider also the indirect evidence in favour of this explanation, for the scar might easily have been overlooked or mistaken for a muscular band. In the first place, gestation in the Fallopian tubes or ovaries may be excluded, for the appendages are quite normal. The development of eight fœtuses to full term would doubtless have left indelible marks upon these organs. There remain the possibilities of primary abdominal gestation and rupture of the uterus or vagina. Against the former view is the complete absence of any 


\section{Pembrey: Sacs in Peritoneal Cavity}

sign of former placental attachment between any of the five sacs and the abdominal organs or parietes. It is true that there, are flakes of lymph scattered about the abdominal wall and viscera, but none of these show under the microscope any other characteristic than that of a fibrinous exudate. Such an exudation would arise as a part of the inflammatory reaction to the expulsion of the fotuses into the abdominal cavity. No abnormal vascularity was observed in any part of the abdomen directly after the death of the animal from poisoning with coal-gas.

It has already been stated that a careful examination of the entire genital tract side by side with the organs of a normal doe showed evidence of a former rupture of the uterine horns about $1 \cdot \mathrm{cm}$. above their opening into the vagina. This scar, which was overlooked when the specimens were exhibited at the meeting of the Obstetrical Society, showed in microscopic sections the presence of fibrous tissue filling the space between the separated muscle of the uterus. The rupture must have occurred at least eight months before the examination of the animal, for in that interval she had four normal litters. From the size and development of the fœtuses in the sacs there is little doubt but that they had reached full term when the rupture took place. Sufficient explanation for the causation of the rupture is found in the fact that four fotuses were enclosed in one sac. Two of these were attached by their umbilical cords to the wall of the sac and within three or four centimetres of each other. The twisted condition of these fotuses and of their umbilical ends would point to the conclusion that it was the impaction of their bodies which caused obstruction to delivery and consequent rupture. Although there is no evidence how this marked torsion was produced, we can come to no other conclusion than that it was caused in the course of labour by the uterine contractions. It is possible that the torsion was subsequently accentuated by the contraction of the inflammatory material, which covered the foetal sacs, and by the absorption of water from the fœtuses.

Previous Work upon the Subject. It is unnecessary to refer in detail to the records of similar specimens of fœtal sacs, which have been found in the peritoneal cavity, for these have been critically examined by Bland Sutton and quite recently by Kamann. The view held by Bland Sutton, that these sacs are not due to extrauterine pregnancy, but to rupture of the uterus and extrusion of the fœtal sacs into the abdominal cavity, would appear to offer a full explanation of the phenomena.

It is well known that rupture of the uterus does occur in animals 
during labour and that a not infrequent cause is a malpresentation or the impaction of a fotus which is too large to traverse the genital canal. The mother in some cases recovers and examination of the uterus some months after the accident may show no obvious scar. Simonds was unable to find any cicatrix in the genital canal of a ewe twelve months after such a rupture. Without a most careful examination, both by dissection and microscopical sections a former rupture of the uterus may be easily overlooked, and thus erroneous conclusions may be drawn.

That the fotal sacs become encapsuled by an inflammatory exudate after their expulsion into the peritoneal cavity, is shown by the experiments of Leopold. This observer placed fresh fœtal sacs in the peritoneal cavity of rabbits, and found that in nine or ten weeks they were covered over with a fibrinous capsule.

It is of interest in connection with the torsion which was observed in some of the fotuses, which have been described in the present paper, to note that axial rotation of the gravid uterus has been observed in the ewe, cow, guinea-pig, cat and hare. Bland Sutton gives references to such cases; in some of these the torsion was so complete that the horn of the uterus was detached.

\section{ReFerences.}

Bland Sutron. "Surgical Diseases of the Ovaries and Fallopian Tubes, including Tubal Pregnancy." London, 1896, p. 319.

Bland Sutron. Journ. Comp. Path. and Therap., June, 1891 ; and Journ. Comp. Med. and Vet. Arch., New York, 1891. Vol. xii., p. 429.

Simonds. Trans. Vet. Med. Ass, 1842-3. Vol. ii., p. 492.

LEOPold. Arch. f. Gynäk., 1881. Bd. xviii., S. 53.

K $\triangle$ MaNN. Monatsschrift f. Geburt. u. Gynäk, 1903. Bd. xvii., S. 588

Pembrey. Trans. Obstet. Soc., London, 1898. Vol. xl., p. 253.

The specimens described in this paper have been presented to the Museum of the Royal College of Surgeons of England. 